\title{
Dental hygienist
}

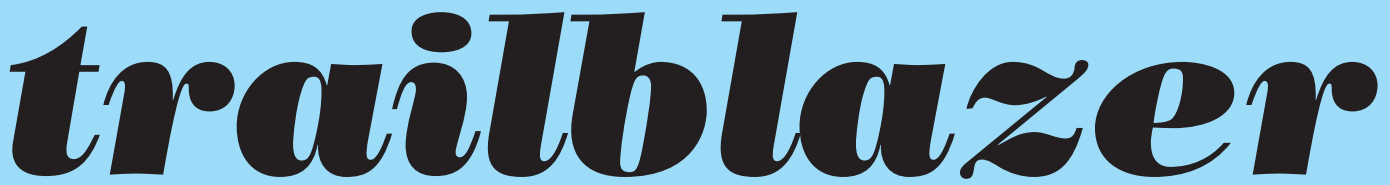

\section{BDJ Team editor Kate}

Quinlan interviews dental hygienist Jo Kennedy, 38, also known as The Sparkle Fairy. Jo has taken advantage of the recent change in rules over direct access to patients and launched her own mobile dental hygiene service.

\section{Can you tell me a bit about} your background?

I was born and raised in Bermondsey in Central London but now live in Surrey. I have been married for almost seven years and have a threeyear-old daughter. We recently moved to Surrey as we wanted a life where we could just go out and have more freedom, trees and green space. When I go back into London - as my parents still live in Bermondsey - the thing that really gets me is how close all the buildings are. They're building flats on top of flats; when you look out your window you're looking into someone else's window. For the first time in my life, I now have a lovely garden, as previously I've always lived in a flat, so we're making the most of it.

\section{Did you always want to work}

in dentistry?

When I was at school I wanted to be a primary school teacher or go into advertising so I did my A-levels to go in that direction. The first thing I realised was that I couldn't spell very well so becoming a primary school teacher wasn't really the best option. Unfortunately I was a child of the 80 s and dyslexia wasn't really spoken about. Once when I was about 11, in history class, I remember writing down the name of a country and my teacher said to me, Jo is that really how you think you spell that word, and I said

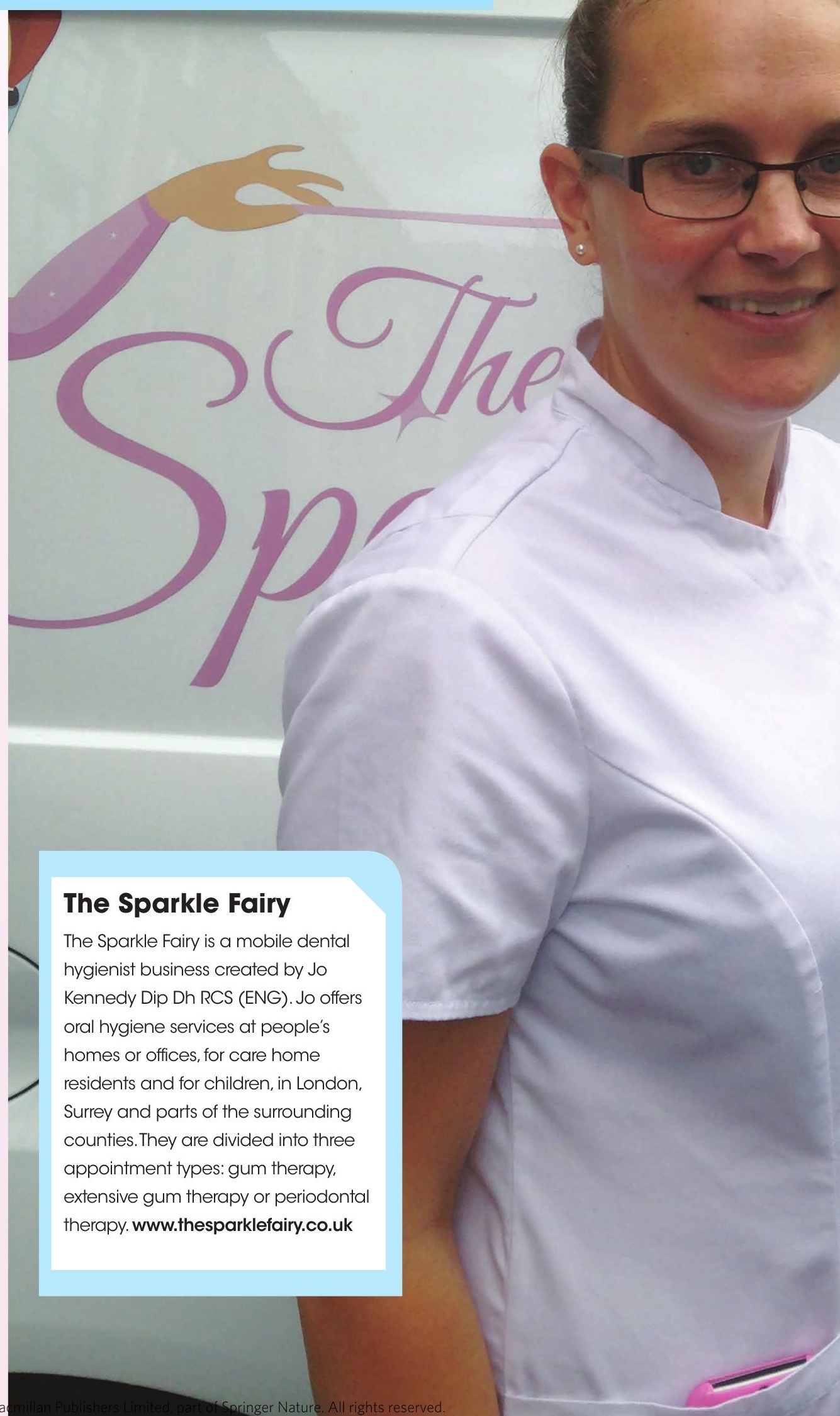


amount of people. We do have a few patients who have googled 'mobile dental hygienist' and found us and I always find those people fascinating. We do anything from 6.30/7 am appointments right through to $9 \mathrm{pm}$. It's a new business so we have chosen to do those hours, get ourselves out there and provide the service for our patients at times that suit them. I think I was a bit naïve at first. I didn't realise that starting my own business would be this hard, this time consuming, but I don't resent it, it's an amazing journey and every day we are helping to open up primary care dental services to those that need them the most.

Thursday mornings I dedicate to my daughter so weve had swimming and gymnastics this morning, had lunch then we'll drop her off to her grandma after this interview, then we have three appointments tonight. When it's your own business it's very difficult to have a cut-off point and not reply to patients and enquiries, whatever day or time. I have been known to be texting patients back at $10 \mathrm{pm}$ on a Sunday night who are a bit anxious about their Monday morning appointment but I can't ignore them; I reply and put their mind at rest.

\section{I see that you also offer tooth whitening on your website. \\ Is it popular?}

Tooth whitening is offered but is not that popular at the moment. I'm not much of a saleswoman to be honest. The reason we want to offer tooth whitening is because illegal tooth whitening really concerns me. It concerns me that people are going out there to use damaging products to whiten people's teeth, performing an act of dentistry when they are not qualified to do so. So I wanted to offer a safe, legal tooth whitening service that is done in the home. It's difficult because when you talk to people, they've heard about beauticians doing it for $£ 50$ and you're telling them it costs much more. When I've cleaned someone's teeth and they say they're interested in tooth whitening I say live with the teeth for a while now that I've cleaned them, and see how you feel. I never want to bombard my patients with buy this, do this, but if they do want whitening they can request it and I will provide it if appropriate with the help of our dentist who applies the first application.

\section{Do you sometimes have to advise patients to see a dentist?}

Yes. For example recently I saw a young man of 29 who had never had anyone look in his mouth - I'll leave that to your imagination - and he had a lot of demineralisation going on in his mouth. So when I had finished with him I asked him to book in with a dentist and told him why he needed to see a dentist. Also, with a patient's permission, if necessary I write to their dentist to outline my findings. All of my patients receive a letter after I have seen them that outlines what I have done, what I have suggested that they need to do and when I need to see them again along with plaque and bleeding scores and/or a six point pocket chart so the patient can keep up with their care. Continuation of care is really important. I'm not taking patients away from dentists but I'm seeing patients who otherwise wouldn't see anyone and in turn encouraging/recommending that they do see a dentist, not just for the health of their teeth but for the health of their mouth, oral cancer screening and so on.

\section{How did you get the word out} about The Sparkle Fairy when you first launched?

When we first launched I used Facebook, loads of posts on our own profiles, then on local parent and other pages to get the word out there. We had CQC clearance in October and had a handful of patients shortly after that, mainly referred by friends. Then in January we really started marketing and using Google ads and many other marketing methods to get the business out there and things have really picked up.

\section{Is it sometimes difficult to cope with demand?}

It's starting to get that way as we don't really want to do weekends when we offer such long hours in the week. But I do book patients in for a Saturday morning if it's urgent and they can't do any other day. We try to accommodate everyone who wants an appointment and can usually deliver within a few weeks of contact, which is pretty good for dental hygiene appointments generally.

How does your husband find the time to travel around in The Sparkle Fairy van with you?

As a firefighter he does shift work so we work around when he's not doing a shift. I have to have someone with me who is trained in certain areas. I'm just lucky that I married a man that already has CRB checks and he is a trained first aider and he's on site as my chaperone.
Do you

enjoy being

on the road

every day and

meeting lots of

different people?

I love it. It's so

intimate: how you get to know your patient in a normal surgery is nothing like how I get to know my patients. I get to meet my patient's family, their pets, see which toys their children play with, what pictures they have in their front room. A lot of trust is involved as I'm going into their home and seeing personal things. They get my full attention so I have the time to chat if they want to and I'm not thinking about getting the next patient through the door as you might be in a practice.

I make the effort to eat healthily and take a packed lunch when I'm on the road as I can't live off fast food. If we're out in the evening I make sure we take food for the whole day prepared at home.

\section{Do you have plans to expand in the future?}

The dream long term is to expand and have a fleet of hygienists all over the country which will open up primary dental care to so many people who are currently unable to access it due to varying reasons, eg disabilities, time constraints, etc.

\section{Would you encourage other DCPs to consider launching their own business?}

Yes $100 \%$ I would. There are a lot of very driven, very caring and enthusiastic hygienists out there and it's hard to have the bravery to say 'actually, I can start my own practice', so it would be great for other hygienists to do it. Setting up my own business has been very challenging and time consuming but it is extremely rewarding in the sense that I have my own patient base that trust and believe in me to better their oral health. I'm looking forward to seeing what the future holds for The Sparkle Fairy and will continue to strive to open up our service to those that need it the most.

bdjteam 2016143 